\title{
Análise patogenética dos distúrbios cognitivos emesquizofrênicos confusionais (Kleist) por meio da prova de Rorschach
}

\author{
Lucia Maria Salvia Coelho ${ }^{1}$ \\ Roberto Fazzani Neto ${ }^{2}$
}

Recebido: 4/4/2003 Aceito: 12/12/2003

RESUMO

Os autores discorrem a respeito das características das formas esquizofrênicas denominadas por Kleist como grupo confusional, diferenciando-o do grupo paranóide. Apresentam quatro casos que, segundo a sistematização feita por Aníbal Silveira, foram considerados inicialmente as formas do grupo confusional: embotamento incoerente, esquizofrenia paralógica, fantasiofrenia e esquizofasia. A partir de uma perspectiva cognitivo-sistêmica, apoiada em conceitos da neuropsicologia, apresentam a análise dos processos cognitivos de cada quadro clínico, estudados por meio do psicodiagnóstico de Rorschach, enfatizando as alterações relacionadas aos diversos sistemas psíquicos, característicos a cada caso. Os autores têm como objetivo evidenciar a contribuição que o exame psíquico efetuado pelo exame de Rorschach pode trazer para o estudo experimental dos processos mentais e suas diversas formas de comprometimento. Unitermos: Cognição; Esquizofrenia; Processos mentais; Rorschach.

\section{ABSTRACT}

Pathogenetic analysis of the cognitive disturbances in confusional schizophrenia (Kleist) through Rorschach's test The authors talk about the characteristics of the schizophrenic forms called by Kleist as the confusional group, differentiating it from the paranoid group. They present four cases that, according to the systematization made by Aníbal Silveira, were considered initially as the forms of the confusional group of schizophrenia: Incoherent, Paralogical, Phantasiophrenia and Schizophasia. From a cognitive-systemic perspective, supported by concepts of the neuro-psychology, an analysis of the cognitive processes of each patient was presented and studied through the psychodiagnostic of Rorschach, emphasizing the alterations related to the different psychic systems, characteristic of each case. Their goal is to make evident that the psychic examination through the Rorschach test can contribute for the experimental study of the mental processes and its different forms of implications.

Keywords: Cognition; Schizophrenia; Mental processes; Rorschach.

Os quadros clínicos das esquizofrenias confusionais* e paranóides já foram abundantemente descritos pela psiquiatria, com denominações diversas, mas só mais recentemente vêm sendo estudados pela neuropsicologia. Entretanto, no campo clínico esses estudos dão maior ênfase aos mecanismos bioquímicos empiricamente definidos a partir dos resultados obtidos pela ação de medicamentos que atenuam a expressão de sintomas psicopatológicos. Os sistemas cerebrais e os processos psicológicos raramente são considerados.

A neuropsiquiatria sistêmica foi desenvolvida por Karl Kleist e, em nosso meio, por Aníbal Silveira, pautado em seu modelo teórico do psiquismo humano.

Kleist reconheceu na esquizofrenia quatro grupos mórbidos autônomos: as formas hebefrênicas, as formas catatônicas, as formas paranóides e as formas confu-

Psicóloga, Doutora em Ciências Médicas, Mestre em Filosofia das Ciências, Especialista em Rorschach, Presidente da Sociedade Rorschach de São Paulo.

2 Médico Psiquiatra, Doutorando em Psiquiatria pela USP, Mestre em Psicologia Social, Professor de Psicopatologia da Universidade São Judas.

* As formas de esquizofrenia confusional descritas por Kleist correspondem de certo modo à forma desorganizada da DSM-IV, ainda que não haja uma correspondência estrita, pois o embotamento incoerente e a esquizofasia corresponderiam mais provavelmente à forma indiferenciada. A dificuldade para encontrar uma correlação mais precisa é decorrente das diferenças nos princípios utilizados na classificação (critérios descritivos na DSM-IV e critérios patogenéticos na nosografia de Kleist). 
sionais, além das parafrenias, mais próximas à esquizofrenia paranóide.

Quando Kleist classifica os quadros esquizofrênicos quanto à evolução, distingue-os em típicos e atípicos. Os quadros típicos correspondem às formas simples nas quais apenas um sistema cerebral é envolvido e comprometido no processo mórbido. São, portanto, quadros sistemáticos e sua evolução, razoavelmente previsível. Os quadros atípicos assim evoluem por duas razões possíveis: ou são formas combinadas, nas quais mais de um sistema cerebral é envolvido no processo mórbido, ainda que de modo previsível, portanto sistemático, ou são formas extensivas, nas quais o processo mórbido amplia-se a diferentes sistemas cerebrais, de modo imprevisível. São, portanto, assistemáticos.

As formas de esquizofrenia confusional devem ser diferenciadas das formas paranóides. Segundo o modelo de Silveira, nas diferentes formas de esquizofrenia paranóide o comprometimento principal se dá na esfera intelectual, envolvendo os processos cognitivos, bem como nas formas de esquizofrenia confusional. No entanto, no grupo paranóide as alterações decorrem do envolvimento de sistemas de outras esferas, tendo como resultado a predominância das concepções delirantes e/ou das alucinações. Já nas formas confusionais ocorre o comprometimento intrínseco das funções cognitivas.

Se no funcionamento normal os sistemas psíquicos, agrupados em unidades mais amplas, as esferas de personalidade (afetividade, conação e cognição), funcionam de modo harmônico, seguindo uma atuação hierárquica entre as diferentes funções que os compõem, este equilíbrio rompe-se em condições patológicas. Assim, é possível diferenciar as diversas funções psíquicas quando essa harmonia desfaz-se pelo processo patológico ou quando elas se organizam nas diferentes fases do desenvolvimento.

A análise patogenética dessa ruptura deverá esclarecer quais esferas e sistemas acham-se primariamente afetadas e de que modo esse distúrbio repercute no conjunto do psiquismo. Este exame apenas será viável se pautado em um modelo teórico de personalidade.
Utilizaremos aqui o modelo sistêmico evolutivo concebido por Aníbal Silveira, pois é o único que abrange as relações do psiquismo com a atividade cerebral, tanto em condições normais como patológicas. A partir desse modelo, Silveira propôs um critério nosológico fundamentado nas concepções psiquiátricas de Kleist sobre as diferentes formas de esquizofrenia (Silveira, 1959, 1962)

Neste trabalho apenas examinaremos alguns quadros clínicos das esquizofrenias confusionais, de modo a elucidar o procedimento que adotamos para o estudo patogenético por meio da prova de Rorschach ${ }^{* * *}$. Utilizamos como referencial teórico o modelo de personalidade elaborado por Aníbal Silveira (Coelho, 1980). Neste modelo, as concepções neuropsicológicas aproximam-se daquelas da escola russa de Vgotskii e Luria e mais recentemente daquelas desenvolvidas por Edelman (1992).

\section{Esquizofrenia confusional: formas clínicas}

A expressão predominante de distúrbios na esfera intelectual ocorre nas esquizofrenias de tipo paranóide e confusional. Enquanto no primeiro grupo as alterações cognitivas decorrem de transtornos nos sistemas afetivocognitivo ou cognitivo-motor (conativo), no grupo confusional evidencia-se alteração intrínseca das funções que compõem os sistemas no interior da esfera cognitiva. Deste modo, neste grupo os distúrbios são mais marcantes e mais bem caracterizados, permitindo a distinção de quatro formas diferentes: embotamento incoerente, paralogia, fantasiofrenia e esquizofasia; mais tarde, Silveira excluiu a fantasiofrenia do grupo das esquizofrenias confusionais, considerando mais apropriado incluí-la entre as formas paranóides ${ }^{* * *}$.

$\mathrm{Na}$ forma incoerente observa-se transtorno intrínseco da elaboração, ou seja, a elaboração das experiências faz-se de modo desorganizado, sem levar em conta o tempo, a sucessão, os aspectos pertinentes e os secundários, as relações entre os objetos. Deste modo, a própria noção imediata do ambiente encontra-se alterada e o raciocínio torna-se incoerente pelo fato de o indivíduo não perceber adequadamente as condições da realidade.

** Este trabalho utiliza os dados dos exames psíquicos referentes aos distúrbios cognitivos de pacientes examinados por Aníbal Silveira em 1980 e dos protocolos da prova de Rorschach aplicados nesta ocasião por Lucia Coelho, a partir dos quais esta autora elaborou uma comunicação ao X Congresso Internacional de Rorschach realizado em Washington, em 1981, focalizando exclusivamente as alterações detectadas no processo de adaptação à realidade. Estamos preparando um outro trabalho com o Dr. Roberto Fazzani Neto, no qual distinguiremos os quadros progressivos e os com evolução benigna (psicoses diatéticas de Kleist).

*** A fantasiofrenia, ainda que descritivamente se assemelhe às formas confusionais, em virtude da desorganização cognitiva, trata-se de uma forma paranóide, por ser delirante. O que confere a característica desorganizada ao pensamento é o fato de os delírios fantásticos envolverem especificamente a função dedutiva, a partir do estímulo afetivo. Como o sujeito que apresenta esse transtorno tira suas conclusões delirantes de modo "intuitivo", não partindo da observação, superficialmente o quadro parece ser de confusão. 
$\mathrm{Na}$ forma paralógica o transtorno mental ocorre no momento da articulação das informações para o raciocínio, por causa de simplificações, desvios e transposições na formação dos conceitos. A alteração ocorre na observação abstrata (noção genérica dos fenômenos), de modo que o indivíduo condensa em uma mesma concepção vários aspectos heterogêneos, chegando a conclusões errôneas e desvinculadas da realidade. Em seu raciocínio, o indivíduo inclui acontecimentos que ocorreram em diferentes épocas, situações, com diferentes pessoas ou objetos. Embora mantenha a noção concreta da realidade, ele parte desses dados para chegar a resultados discrepantes. Nesta forma de esquizofrenia observa-se alteração extrínseca da capacidade de elaboração, ou seja, o transtorno do raciocínio decorre de simplificações, desvios e transposições na formação de conceitos.

$\mathrm{Na}$ fantasiofrenia o pensamento acha-se comprometido na fase inicial do processamento simbólico (atribuição de significados), e não propriamente em sua construção, como no caso anterior. Ocorre a utilização adequada dos dados do ambiente, porém com atribuição de significados simbólicos particulares. O desenvolvimento de concepções não se acompanha da devida retificação diante dos fatos da realidade externa. No delírio, ocorrem transformações no mundo e nele próprio (delírio catastrófico) e essas transformações independem da vontade do paciente. O delírio fantástico apresenta-se como alteração da elaboração dedutiva.

Na forma esquizofásica acha-se afetada primariamente a capacidade de comunicação, principalmente verbal e eventualmente gráfica, acarretando alterações secundárias nos demais níveis de processamento das informações. A este respeito, Kleist pondera: "Com uma confusão ideativa tão grave quanto a da linguagem, não se poderia compreender a persistência durante anos de um comportamento invariavelmente adequado. Diante disso, é forçoso admitir que existem diversas formas de pensamento, entre elas um pensamento lógico, abstrato, estreitamente ligado à linguagem, e por ela dirigido, e um pensamento na atuação, ideomotor, técnicofuncional. Seguramente, nas esquizofazias está alterado o primeiro, enquanto o comportamento racional, a atividade e o trabalho sensatos evidenciam a integridade do último" (apud - Spartaco Vizzotto e Isaias Mehlson, em Esquizofasia, 1959).

Antes de expormos os principais resultados obtidos por meio da prova de Rorschach, aplicada em pacientes com diagnóstico de diferentes formas de esquizofrenia confusional, faremos algumas considerações sobre as funções e os sistemas psíquicos que compõem a esfera cognitiva da personalidade.

\section{Esfera cognitiva}

A esfera cognitiva corresponde ao conjunto das funções psíquicas que presidem a noção de realidade, o processamento das experiências com o meio externo e interno e as modalidades de categorização dessas experiências, resultando na adaptação contínua e progressiva do ser humano às condições do ambiente físico e social. Na atividade cerebral, essas funções são regidas pelos sistemas do lobo frontal.

Desde o nascimento, as funções que compõem as três esferas da personalidade mantêm uma interação íntima, mas não arbitrária, o que permite a distinção em sistemas, sendo as funções afetivas as mais básicas para a sobrevivência e a manutenção das relações interpessoais, e as funções cognitivas as mais complexas e dependentes. Desse modo, as funções afetivas influenciam a ativação das funções cognitivas (interesse) e das funções conativas (motivação), sofrendo por sua vez o impacto das concepções intelectuais (emoção), mas não diretamente das funções conativas. Essa harmonia psíquica decorre da existência interpessoal, variando em sua reestruturação no decorrer das diferentes fases de desenvolvimento somático e histórico-social.

$O$ resultado da atividade de sistemas cerebrais específicos e dos processos psíquicos mobilizados permite a distinção de cinco funções na esfera cognitiva, correspondendo aos diferentes níveis do trabalho mental, apenas isoladas de modo teórico, uma vez que não se desenrolam de modo independente, nem em uma simples sucessão linear. Os processos cognitivos, tal como foram definidos por Silveira, vêm sendo atualmente investigados de modo experimental pela psicologia cognitivista (Barlow, 1990; Lazarus, 1991; e Bastien 1997).

A evidência empírica da expressão de cada nível dos processos cognitivos apenas pode ser obtida com o estudo sistemático da evolução psicogenética do ser humano ou ainda pela utilização do método patológico. Em ambos os casos, a prova de Rorschach oferece um paradigma experimental interessante para a análise dos processos psíquicos, que correspondem ao plano mais diferenciado e dependente da atividade cerebral (expressão psicológica). Durante essa prova são mobilizadas diferentes funções mentais, e no caso específico dos processos cognitivos ela permite o exame dos diferentes níveis de processamento das informações.

$\mathrm{Na}$ fase inic ial do processamento cognitivo distinguimos as funções da observação concreta e abstrata (dos eventos particulares e imediatos ou dos fenômenos genéricos apreendidos por abstração) que presidem o contato inicial com o ambiente e que supõem o processo perceptual (uma das funções de ligação com o ambiente) 
por meio da integração das informações dos diferentes órgãos sensoriais, cujo funcionamento seletivo depende do concurso das funções conativas ou psicomotoras (desencadeamento, manutenção e seletividade da atenção). Nessa fase do trabalho mental, o indivíduo distribui sua atenção pelos diferentes estímulos exteroceptivos (campo perceptual), focalizando de modo seletivo determinados aspectos do ambiente, segundo um ritmo e estilo que lhe é peculiar (estilo perceptual, indicado no Rorschach pelos índices Perc e Suc) e em função das condições objetivas do ambiente (avaliado no Rorschach pelo índice F e pela proporção entre fatores determinantes). Partindo de suas experiências anteriores, o indivíduo extrai as informações que lhe parecem pertinentes e significativas no momento atual (memória de trabalho, na acepção que Baddeley estabeleceu em 1986 (apud Tiberghien, 1997) indicada no Rorschach pela produtividade associativa e pelo valor quantitativo do índice lambda). O resultado da atividade dessas duas funções cognitivas é a noção da realidade, cuja imagem mental correspondente é a imagem primária, appraisal primário, segundo Lazarus, ou consciência primária, na acepção de Edelman.

Na segunda fase ocorre a elaboração da noção, ou o pensamento de onde resulta a imagem subjetiva, construída sobretudo pela atividade reflexiva peculiar ao ser humano (consciência secundária, na acepção de Edelman), necessariamente influenciada pela ressonância emocional que a acompanha. $\mathrm{O}$ modo com que o indivíduo utiliza informações mobilizadas de suas experiências passadas decorre da modalidade específica de reflexão. Esta fase de processamento dá-se por meio das funções indutiva e dedutiva, correspondentes a modalidades diversas de raciocínio, que permitem respectivamente o estabelecimento de relações imediatas por comparação, ou de relações dinâmicas por sucessão, de onde se extraem as consequiências de ordem mais geral. A análise desses tipos de raciocínio efetua-se no Rorschach pelas modalidades de imagens $R$ indutivas/ $R$ dedutivas $e$ ainda pelos fatores determinantes, enquanto o modo e a intensidade com que o indivíduo mobiliza suas experiências passadas para elaborar uma situação atual, com intervenção maior ou menor do julgamento crítico (executor central), podem ser avaliados pela análise dos índices lambda e sua relação com $\mathrm{F}+$ ).

Enfim, a codificação do pensamento faz-se pelo processo de simbolização, em que a simplificação da imagem subjetiva estrutura-se como signos (indícios, sinais e símbolos), sendo então fixados na memória a longo termo, que abrange inclusive a assim chamada memória afetiva, mas este armazenamento faz-se de modo dinâmico (esquemas), e não como simples engramas. Esta fase influencia e é influenciada de modo direto pelos processos da fase anterior, daí os diferentes tipos de construção de imagem no Rorschach (Coelho, 1992). Ao mesmo tempo, essa categorização das experiências por meio da linguagem expressa-se nas diferentes modalidades de comunicação: mímica, verbal e abstrata (no Rorschach representados pelas categorias de conteúdos). No Rorschach, o estudo diferencial das situações dominantes no decorrer desses processos cognitivos é feito de modo paradigmático pela análise em separado dos índices e fatores avaliados no conjunto de estímulos coloridos, mobilizadores diretos das reações afetivas (conjunto color), e no de estímulos monocromáticos, que favorecem o julgamento imparcial dos fatos (conjunto mono).

Este processamento cognitivo supõe a atividade combinada de estruturas cerebrais e de fatores sociais, seletivos e estimulantes. As ligações mantidas com a atividade dessas funções cognitivas não se fazem de modo direto, mas decorrem da intervenção de alças de retroação que permitem a integração do trabalho mental. $\mathrm{O}$ resultado dessa integração dificulta a apreensão específica da intervenção de cada uma das funções no processamento das informações em estudos sobre o comportamento, exigindo portanto a intervenção de instrumentos, como o Rorschach e alguns exames neuropsicológicos, quando for o caso. Além disso, as ligações intersistêmicas com as funções das outras esferas da personalidade torna ainda mais sutil a análise dos componentes dos processos cognitivos tal como eles se expressam no comportamento, o que torna indispensável a utilização de um modelo teórico de representação sistêmica dos processos envolvidos.

Desse modo, o Rorschach permite a análise mais objetiva e específica dos fenômenos psicopatológicos perceptuais, ideativos e expressivos que ocorrem em indivíduos esquizofrênicos. Pretendemos aqui expor apenas nosso procedimento técnico com a prova de Rorschach para a análise diferencial de distúrbios cognitivos específicos, observados em diferentes formas de esquizofrenia confusional; uma vez que o nosso propósito limita-se ao exame das funções cognitivas, não levaremos em conta os demais fatores e índices do Rorschach que permitem a avaliação das funções afetivas e psicomotoras. Os conceitos teóricos e operacionais da prova de Rorschach são referidos de modo mais específico em trabalhos especializados (Silveira, 1964; Coelho et al., 2002).

\section{Pacientes examinados}

Estes pacientes apresentam como sintomas primários a desorganização na construção do raciocínio, 
resultando em um discurso incoerente, com alogias e paralogias, além de, por vezes, apresentarem concepções delirantes. Estas, com exceção do caso da fantasiofrenia, são fragmentárias e não são centrais como sintomatologia. Por vezes, a sintomatologia também é composta de alterações sensoperceptuais (alucinações e automatismo mental) interferindo na noção e na adaptação à realidade.

Selecionamos quatro protocolos de pacientes do Hospital do Juqueri, todos do sexo masculino, diagnosticados em 1980 por Aníbal Silveira como apresentando diferentes formas confusionais de esquizofrenia. Nesta época, o procedimento habitual do Pavilhão Escola de Franco da Rocha para com os pacientes internados consistia na entrevista psicológica e na aplicação do Rorschach, após a realização dos exames psiquiátricos, desde que as condições mentais dos pacientes o permitissem. Neste trabalho, apenas destacamos no exame psíquico os transtornos cognitivos, pois não pretendemos realizar um estudo de casos tal como é feito pela clínica, mas fazer uma análise específica de uma determinada modalidade de transtornos observados em pacientes esquizofrênicos. Neste estudo, o exame dos dados fornecidos pela prova de Rorschach segue as diretrizes teóricas do modelo de Silveira e nele se incluem técnicas cognitivistas mais atuais de análise do processo de construção de imagens (Coelho, 1992).

Em virtude do nível de trabalho mental primariamente atingido, distinguimos para cada paciente a expressão de uma forma clínica diversa: embotamento incoerente, paralogia, fantasiofrenia e esquizofasia, lembrando que, na época do exame, a idade dos pacientes era respectivamente 43, 57, 65 e 45 anos.

Os dados da prova de Rorschach foram examinados em dois planos distintos: o plano das estruturas formais presente em cada psicograma - as interações específicas entre as áreas abrangidas nas respostas a partir dos movimentos oculares e dos focos da atenção, que definem o estilo perceptual, ou seja, o modo com que cada paciente observa o ambiente (no caso, por meio da percepção visual), os fatores determinantes na construção das imagens, indicando os desvios específicos do pensamento indutivo ou dedutivo; e as categorizações verbais que elucidam os diferentes modos de simbolização das experiências e o plano preconceitual, que corresponde aos mecanismos de reação que intervieram na apreciação e na elaboração dos estímulos do Rorschach.

\section{Esquizofrenia - formas confusionais}

Uma vez que nosso propósito é elucidar os mecanismos subjacentes às alterações observadas nos distúrbios cognitivos, e não efetuar estudo de casos clíni$\cos$, mencionaremos apenas os dados mais significativos do exame psíquico nesses pacientes.

\section{Síntese dos exames psíquicos}

\section{Embotamento incoerente}

Durante o exame revelou dificuldade em perceber a situação em que se encontrava, não se orientando no ambiente e no tempo. Elaboração incoerente dos dados externos. Perda da noção do tempo e da capacidade de associação lógica. A interpretação das experiências afetivas e da atividade prática encontra-se falseada por julgamentos de valor.

\section{Esquizofrenia paralógica}

O paciente consegue perceber razoavelmente sua situação no hospital, apesar de desorientado no tempo. Apresenta alterações sensoperceptivas do tipo automatismo mental verbal-auditivo. Embora mantenha um bom contato afetivo com o examinador, o paciente teve dificuldade em expor suas idéias, suas concepções não seguem a lógica formal, evidenciando freqüentes paralogias em seu discurso, porém não apresenta concepções delirantes sistematizadas. A confusão mental impede a seleção dos conceitos pertinentes para ele expressar uma idéia.

\section{Fantasiofrenia}

O paciente revelou-se expansivo, expressando longamente suas concepções delirantes. Apreende adequadamente as situações cotidianas, ainda que tenda a atribuir a algumas delas significados simbólicos. Ausência de alucinações ou de automatismo mental.

Refere que foi internado pela primeira vez quando tinha 36 anos de idade. Diz ter caído de um de seus aviões e ter sofrido uma lesão pulmonar. Ele e o seu irmão já se encontravam no avião no céu no momento de seu nascimento. Agora este avião está no museu do Ipiranga. Quando ele nasceu ele era o reizinho de ouro, pois tinha um busto de ouro no tesouro nacional. Fez então a carreira de Deus de Ouro. É um homem de negócios, possui vários edifícios no mundo e também várias firmas com seu nome traduzido. Ele é casado com estas firmas e suas esposas são as donas da firma junto com ele. Na Alemanha, o nome da firma é Macomani, no Japão é Sokonikiko, na Turquia é Mustada Kako Massamer. Todas essas firmas têm filhos que o ajudam nos negócios. Aos 15 anos foi presidente da Búfalo e da Colômbia. Depois disso foi presidente, em 1939, e chamava-se na época Joaquim Carneiro Leite. Ele não morreu como os outros porque 
ele é Deus, apenas foi mudando de identidade. Refere ainda ter várias cores, quando é branco ele enxerga com os dois olhos e quando fica preto enxerga só com o olho direito. Tem também outras cores. Visita outros mundos com os seus aparelhos. Já esteve em Marte duas vezes. A estrela que gira ao redor do Universo I deixa um rastro de gasolina branca. Já esteve em quatro mundos do Universo I.

O curso do pensamento, tanto na entrevista como no Rorschach, apresenta-se acelerado, porém consegue coordenar e comunicar as suas idéias de modo adequado, elaborando de modo coerente, mas sem nortear-se pelo julgamento de realidade. Parece-me que as diferentes identidades que ele se atribui correspondem a diversos papéis e aparências por ele assumidas no transcorrer das épocas, não havendo uma perda ou cisão da identidade subjetiva.

\section{Esquizofasia}

O paciente manteve um contato afetivo adequado, conseguindo mesmo estabelecer satisfatória comunicação verbal. Porém, no decorrer da entrevista ele começou a falar de modo desconexo, incompreensível, acompanhado de aparente modulação afetiva e gesticulação que contrastam com o modo com que verbalizava suas idéias.

\section{Prova de Rorschach: resultados formais}

Observação: exame da distribuição e focalização da atenção durante a observação concreta ou abstrata dos estímulos visuais do ambiente

\section{Embotamento incoerente}

- Tipos de percepção: Monocromáticas: (G) P2 p Coloridas: G P p2.

- Qualidade formal: Observação da mancha como um todo (Global) :

Mono: $\mathrm{G}^{+}$; Color: $\mathrm{G}$

Pormenores: evidentes $(\mathrm{P})$ e minúcias (p): Mono e Color: P má qualidade formal e p contorno vago.

- Sucessão: Incoerente.

- Tipos de G: Imediato como reconhecimento (22\%); sincrético (55\%), vago, impreciso (23\%).

- Tipos de P: Imediato, concreto (26\%); sincrético (64\%); vago (10\%).

- Estilo de percepção: Atenção mobilizada de modo instável, variando com a presença de estímulos cromáticos (impacto afetivo direto).
A característica que prevalece em seu modo de distribuir a atenção aos estímulos externos é a mudança de uma focalização predominante aos aspectos concretos e imediatos em situações de ordem impessoal, aos quais atribui significados arbitrários (P2 com má qualidade formal), para a atração dominante que estruturas mal definidas, despercebidas pela maioria, provocam no paciente (p2 em formas vagas) quando se defronta com situações de ordem afetiva. Apesar dessa diversidade no modo de o examinando observar os dados concretos, quando o paciente consegue abranger sua atenção para o conjunto total dos estímulos (G), ele tende a integrá-los de modo arbitrário, sem levar em conta as propriedades estruturais (entre as respostas globais prevalecem aquelas do tipo $\mathrm{G}$ sincrético em todo o protocolo).

\section{Esquizofrenia paralógica}

- Tipos de percepção: Monocromáticas: G2 P Coloridas: P2 p.

- Qualidade formal: Observação da mancha como um todo $(\mathrm{G})$ :

Mono: Gr; Color: G. Pormenores: evidentes (P) e minúcias (p): Mono e Color: má qualidade formal e $\mathrm{p}$ contorno vago.

-Sucessão: Incoerente.

- Tipos de G Imediato, como reconhecimento (40\%); sincrético (60\%).

- Tipos de P: Imediato, concreto (36\%); sincrético (64\%).

-Estilo de percepção: Atenção mobilizada de modo instável, variando com a presença de estímulos cromáticos (impacto afetivo direto).

A característica que prevalece em seu modo de distribuir a atenção aos estímulos externos é a mudança drástica em seu modo de focalizar a atenção. Assim, diante de circunstâncias formais o examinando busca incluir diferentes aspectos dos estímulos em um conceito mais abrangente e abstrato, ainda que demasiadamente subjetivo (G-), embora capaz de reagir aos dados concretos e evidentes do ambiente $(\mathrm{P})$; por outro lado, quando sob impacto afetivo direto, ele se limita a estabelecer ligações arbitrárias entre os aspectos mais concretos das situações, pois ainda que se mostre sensível a pormenores menos evidentes, já não consegue observar as situações sob um prisma mais amplo.

\section{Fantasiofrenia}

- Tipos de percepção: Monocromáticas: G2 Coloridas: G4 E GE 2.

- Qualidade formal: Observação da mancha como um todo $(\mathrm{G})$ : 
Mono: $\mathrm{G}$ negativo, Color: $\mathrm{G}$ com formas não avaliáveis estatisticamente pelo seu caráter idiossincrático. Pormenores evidentes $(\mathrm{P})$ : Mono: P negativo, Color: ausente. Espaços em branco (E) e GE: apenas nas Color com qualidade idiossincrática.

- Tipo de sucessão: Ordenada.

-Tipos de G. Simples, imediato ou sincrético (75\%); vago, superficial (12,5\%); combinado, integrado $(12,5 \%)$.

- Tipos de P: Concreto (25\%), vago, não limitado $(75 \%)$.

\section{- Estilo perceptual:}

Os elementos percebidos não são considerados partes constitutivas de um objeto ou de uma situação concreta, mas são considerados indícios a partir dos quais ele deve compreender a idéias genéricas e abstratas. Deste modo, prevalece a modalidade $\mathrm{G}$ do tipo sincrético, indicando que suas elaborações delirantes interferem no contato direto e concreto com o ambiente (rebaixamento de P; quando ocorre, é apreendido de modo vago), fazendo com que o examinando mantenha uma atitude contemplativa, com reflexões irracionais.

A tendência em apreender as experiências como um todo, atribuindo significados arbitrários, acentuase quando submetido à estimulação afetiva direta. Em tais circunstâncias, encontra significados mesmo na ausência de estímulos (espaço entre as manchas), tentando integrá-los em uma concepção mais genérica e abstrata dos fatos (GE).

\section{Esquizofasia}

-Tipos de percepção: Monocromáticas: G P E Coloridas: P (p) E.

- Qualidade formal: Observação da mancha como um todo $(\mathrm{G})$ :

- Mono: $\mathrm{G}$ positivo, Color: ausente. Pormenores evidentes (P): Mono: positivo, Color: negativo. Espaços em branco (E): Mono: indeterminado $\left(C^{\prime}\right)$, Color: positivo.

- Tipo de sucessão: Indeterminada.

-Tipos de G: Simples, imediato (50\%); vago, superficial (50\%).

- Tipos de P: Concreto (78\%); vago, não limitado $(22 \%)$.

- Tipos de E Delimitado (Rev) (68\%); vago e arbitrário (32\%).

\section{- Estilo perceptual:}

O estilo perceptual mantém-se no protocolo, apesar de certa variação em função da natureza dos estímulos observados: os estímulos que representam situações impessoais foram apreendidos de modo global e imediato, correspondendo a formas adequadas de reconhecimento dos padrões configuracionais. Quando estimulado afetivamente, ainda que mantenha o estilo perceptual dominante, o examinando não consegue perceber o conjunto dos estímulos por se ater a pormenores insignificantes (p). De um modo geral, prevalece a observação concreta e imediata dos fatos associada à tendência em observar os obstáculos que encontra no ambiente (Reversão figura-fundo).

\section{Elaboração das experiências: estudo do pensamento e da memória}

\section{Embotamento incoerente}

\section{- Capacidade associativa:}

$\mathrm{R}=58 \mathrm{R}($ Mono $=23$; Color $=35)$.

Na elaboração das respostas o examinando revelou intensa alteração do pensamento, ocorrendo construções arbitrárias e mal definidas, embora se encontre elevado o processo associativo, sobretudo quando submetido a impacto afetivo direto.

- Organização e integração das experiências:

\section{$\mathrm{Z2}$ (pensamento irracional) $>\mathrm{Z1}$ (pensamento} racional):

Mono: $\mathrm{Z} 1=0,22, \mathrm{Z} 2=0,83$; Color: $\mathrm{Z1}=0, \mathrm{Z} 2=1,08$.

A articulação que estabelece entre as imagens percebidas baseia-se predominantemente em nexos irracionais pautados em concepções subjetivas que interferem em seu raciocínio, e isto ocorre em qualquer tipo de situação, ainda que se intensifique quando o examinando encontra-se sob impacto afetivo.

- Modalidade de imagens: tipos de processamento de informações:

Mono: $\mathrm{R} 1=47 \%($ desvio $=+45)$;

$\mathrm{R} 2=32 \%($ desvio $=-35) ; \mathrm{R} 4=21 \%($ desvio $=+15)$.

Color: $\mathrm{R} 1=56 \%($ desvio $=+54)$.

$\mathrm{R} 2=30 \%($ desvio $=-18) \mathrm{R} 4=14 \%($ desvio $=+6)$.

Entre os seis principais tipos de processamento, apenas ocorreram três: R1, correspondendo a impressões imediatas por evocação de nexos irracionais com estruturação insuficiente; R2, correspondendo a reconhecimento indutivo de padrões formais semelhantes àqueles observados em objetos do ambiente, e R4, correspondendo a imagens em que ocorre condensação afetiva, integrando de modo sincrético significados afetivos e aspectos formais do ambiente. 
- Mobilização da memória:

Monocromáticas: Lambda: 0,64 (desvio $=+0,19)$

$\% \mathrm{~F}=61,0($ desvio $=-4,0)$.

Color: Lambda: 0,35 (desvio $=-0,21) \% \mathrm{~F}=74,0$

$($ desvio $=+6,0)$.

O paciente revela comprometimento na capacidade de mobilizar os recursos adaptativos desenvolvidos em experiências passadas para enfrentar situações atuais $\left(\mathrm{C}^{\prime}=\mathrm{L}=1\right)$.

Em circunstâncias de ordem impessoal, o examinando desconsidera as condições do ambiente externo $(\% \mathrm{~F})$, deixando-se invadir por evocações desconexas ou imaturas $\left(\operatorname{Pos}=4,1=l^{\prime}=1\right)$ que sobrepujam os recursos de ordem adaptativa e atual, interferindo na seletividade de sua memória de trabalho.

O desvio é oposto quando examinamos a mobilização dos recursos subjetivos, disponíveis na memória, quando o examinando encontra-se sob impacto afetivo. Neste caso ele fica à mercê das condições externas $(\% \mathrm{~F})$ reagindo de modo imediato sem levar em conta as experiências passadas.

Portanto, fica evidente o transtorno básico na mobilização seletiva da memória para a elaboração das experiências na construção das concepções. Este processo ocorre de modo desorganizado, não-seletivo, e, ao estabelecer relações entre objetos ou eventos, o examinando confunde os aspectos pertinentes e predominantes com aqueles de ordem secundária ou com conotação afetiva.

\section{Esquizofrenia paralógica}

- Capacidade associativa:

$\mathrm{R}=36 \mathrm{R}($ Mono $=11$; Color $=25)$.

$\mathrm{Na}$ elaboração das respostas o examinando revelou dificuldade em coordenar seu pensamento. Apesar da ocorrência de um certo bloqueio associativo, mostrou-se capaz de construir um número razoável de imagens quando estimulado afetivamente.

\section{- Organização e integração das experiências:}

Z2 (pensamento irracional) $>$ Z1 (pensamento racional):

Mono: $\mathrm{Z} 1=0,50 ; \mathrm{Z} 2=1,20$.

Color: $\mathrm{Z} 1=0,44 ; \mathrm{Z} 2=0,98$.

A articulação que estabelece entre as imagens percebidas baseia-se predominantemente em nexos, pautados em construções paralógicas ou em sobreposição de conceitos heterogêneos. Este tipo de raciocínio manteve-se durante toda a prova.
- Modalidades de imagens: tipos de processamento de informações:

Mono: $\mathrm{R} 1=6 \%($ desvio $=+4)$.

$\mathrm{R} 2=2 \%($ desvio $=-65) \mathrm{R} 4=92 \%($ desvio $=+86)$.

Color: $\mathrm{R} 1=22 \%($ desvio $=+20)$.

$\mathrm{R} 2=26 \%($ desvio $=-22)$.

$\mathrm{R} 4=52 \%($ desvio $=+46)$.

Entre os seis tipos principais de processamento, apenas ocorreram três: R1, correspondendo a impressões imediatas por evocação de nexos irracionais com estruturação insuficiente; mais raramente as R2, que correspondem a reconhecimentos indutivos dos padrões formais do ambiente, e sobretudo as R4, imagens em que ocorre condensação afetiva, integrando de modo inadequado, mas indutivo, significados afetivos e aspectos formais do ambiente.

- Mobilização da memória:

Monocromáticas: $\operatorname{Lambda}=0,22($ desvio $=0)$

$\% \mathrm{~F}=82,0($ desvio $=0)$.

Color: Lambda $=0,32($ desvio $=-0,24)$.

$\% \mathrm{~F}=76,0($ desvio $=+8)$.

O examinando revela acentuada dificuldade de mobilizar os recursos adaptativos desenvolvidos em experiências passadas para enfrentar situações atuais. Apesar do bloqueio associativo revelado pelo examinando quando diante de circunstâncias impessoais (R), ele não se retrai diante do ambiente (\%F mono), conseguindo mobilizar suficientemente seus recursos adaptativos $\left(\mathrm{C}^{\prime}=2\right.$, monocromáticas), ainda que essa dificuldade acentue-se quando ele se encontra sob impacto afetivo $\left(\mathrm{CF}=4, \mathrm{ps}=1, \mathrm{C}^{\prime}=1\right)$.

\section{Fantasiofrenia}

- Capacidade associativa:

$\mathrm{R}=14 \quad \mathrm{R}($ Mono $=6$ Color $=8)$.

Se na entrevista o examinando apresenta inúmeras fabulações, os estímulos do Rorschach facilitam ainda mais a sua ocorrência. $O$ paciente não consegue produzir um número suficiente de respostas codificáveis em razão de os estímulos provocarem intensa liberação associativa, que levam o examinando a afastar-se da prova.

- Organização e integração das experiências: Z2 (pensamento irracional) $>$ Z1 (pensamento racional).

Mono: $\mathrm{Z} 1=1,08 ; \mathrm{Z} 2=0,67$.

Color: $\mathrm{Z1}=0 ; \mathrm{Z} 2=2,44$.

Embora capaz de articular de modo coerente as imagens construídas em estímulos monocromáticos (Z1), quando submetido a estímulos cromáticos que mobilizam diretamente a afetividade, a elaboração do examinando apenas se pauta em nexos irracionais (Z2). 
- Modalidades de imagens: tipos de processamento de informações:

Mono: $\mathrm{R} 1=14 \%($ desvio $=+12) ; \mathrm{R} 2=57 \%$

$($ desvio $=-10) ; \mathrm{R} 4=14 \%($ desvio $=+8)$.

Color: $\mathrm{R} 1=57 \%($ desvio $=+55) ; \mathrm{R} 2=0 \%$

$($ desvio $=-48) ; \mathrm{R} 4=29 \%($ desvio $=+21)$.

Entre os seis tipos principais de processamento, apenas ocorreram três: R1, correspondendo a impressões imediatas por evocação de nexos irracionais com estruturação insuficiente; R2, correspondendo a reconhecimento indutivo de padrões formais semelhantes àqueles observados em objetos do ambiente, e R4, correspondendo a imagens em que ocorre condensação afetiva, integrando de modo sincrético significados afetivos e aspectos formais do ambiente. Entretanto, o único processamento racional (R2) deixa de ocorrer quando o examinando é estimulado afetivamente $(\mathrm{R} 2=0$ no conjunto cromático, no qual apenas ocorrem os mecanismos irracionais, R1 e R4).

\section{- Mobilização da memória:}

Monocromáticas: $L a m b d a=0,50($ desvio $=+0,05)$ $\% \mathrm{~F}=67($ desvio $=0)$.

Color: Lambda $=3,00($ devio $=+2)$.

$\% \mathrm{~F}=25($ desvio $=-21)$

O examinando revela comprometimento na capacidade de mobilizar os recursos adaptativos desenvolvidos em experiências passadas para enfrentar situações atuais $\left(C^{\prime}=1\right)$. Em circunstâncias de ordem impessoal, o examinando leva em conta as condições do ambiente externo $(\% \mathrm{~F})$, intervindo uma concepção imatura de sua posição no ambiente $(\mathrm{ps}=1)$, mas já com tentativa de integração emocional $\left(\mathrm{C}^{\prime}=1\right)$.

O comprometimento desse processo fica evidente quando o examinando encontra-se sob impacto afetivo. Nesse caso, ele se afasta das condições externas $(\% \mathrm{~F})$ expressando de modo imaturo seus afetos $(\mathrm{CF}=5) \mathrm{e}$ recorre a concepções irracionais $\left(\mathrm{m}^{\prime}=1\right)$.

\section{Esquizofasia}

\section{- Capacidade associativa:}

$\mathrm{R}=38 \quad \mathrm{R}($ Mono = 16; Color $=22)$.

A capacidade associativa do examinando acha-se preservada, o que indica que ele é capaz de mobilizar sua memória de modo a conceber significados aos estímulos do ambiente.

- Organização e integração das experiências:

Z2 (pensamento irracional) $>$ Z1 (pensamento racional):

Mono: $\mathrm{Z} 1=0,31 ; \mathrm{Z} 2=1,06$.

Color: $\mathrm{Z} 1=0,52 ; \mathrm{Z} 2=0,57$.
O examinando não consegue articular suficientemente as imagens percebidas ( $\mathrm{Z} 1 \mathrm{em}$ todo o protocolo e o Z2 no conjunto cromático apresentam valor inferior ao mínimo esperado). Entretanto, suas concepções apenas resultam de um trabalho indutivo de comparação, sendo escassamente elaboradas. Apenas diante de circunstâncias formais ele consegue integrar suas imagens em um conceito mais amplo, mas o faz de modo irracional e arbitrário. Uma vez que suas concepções apenas resultam de um trabalho indutivo de comparação, suas experiências são escassamente elaboradas. Este índice avalia a capacidade de elaboração conceptual, o que é mais dependente da linguagem verbal.

\section{- Modalidades de imagens: tipos de processa-} mento de informações:

$$
\begin{aligned}
& \text { Mono: } \mathrm{R} 1=36 \%(\text { desvio }=+34) ; \\
& \text { R2 }=57 \%(\text { desvio }=-10) ; \mathrm{R} 3=0 \\
& \text { R4 =7\% (desvio }=+1) \\
& \text { Color: } \mathrm{R} 1=40 \%(\text { desvio }=+38) ; \\
& \text { R2 = 33\% (desvio }=-15) ; \mathrm{R} 3=20 \%(\text { desvio }=-8) \\
& \text { R4 }=7 \%(\text { desvio }=+1)
\end{aligned}
$$

Entre os seis tipos principais de processamento, ocorreram quatro: R1, correspondendo a impressões imediatas por evocação de nexos irracionais com estruturação insuficiente; $\mathrm{R} 2$, correspondendo a reconhecimento indutivo de padrões formais semelhantes àqueles observados em objetos do ambiente; R3, que decorre de maior capacidade construtiva indutiva, decorrente da avaliação de diferentes propriedades das situações; e R4, correspondendo a imagens em que ocorre condensação afetiva, integrando de modo sincrético significados afetivos e aspectos formais do ambiente.

Portanto, ainda que prevaleçam as imagens sincréticas, neste protocolo os desvios na capacidade de elaboração indutiva das imagens (R2 e R3) são menores que os dos demais, evidenciando menor comprometimento no processamento das informações.

\section{- Mobilização da memória:}

Monocromáticas: Lambda $=0,14$ (desvio = -0,20) $\% \mathrm{~F}=85,7($ desvio $=+2,5)$.

Coloridas: $L a m b d a=0,47($ desvio $=-0,09) \% \mathrm{~F}$

$=68,2($ devio $=0)$.

Ainda que sua capacidade de mobilizar os recursos adaptativos desenvolvidos em experiências passadas para enfrentar situações atuais encontre-se reduzida ( $\mathrm{Ps}=1$, $\left.\mathrm{C}^{\prime}=1, \mathrm{FC}=1\right)$, o seu comprometimento é menor em relação aos demais pacientes, uma vez que ele se mostra capaz de refletir sobre sua posição atual no ambiente (Ps) e de alcançar adaptação afetiva e emocional concreta (FC e $\left.C^{\prime}\right)$ às situações. No caso, a dificuldade que encontra em mobilizar a memória decorre do modo imediato com que reage ao ambiente $(\% \mathrm{~F})$. 
Processo de adaptação à realidade

\section{Embotamento incoerente}

- Julgamento de realidade : $\% \mathrm{~F}+$

Corresponde à capacidade de estabilizar a atenção, mantendo suficiente flexibilidade mental para o julgamento impessoal e objetivo dos fatos.

Mono: $\% \mathrm{~F}+=53,8($ desvio $=-26,2)$;

Color: $\% \mathrm{~F}+=47,6($ desvio $=-28,4)$.

Alteração no julgamento de realidade diante de qualquer tipo de experiência.

Adoção dos padrões de pensamento do adulto: $\% \mathrm{~V}$

A integração à realidade supõe a integração de valores convencionais de comportamento no psiquismo, definindo padrões de pensamento adotados pela maioria.

Mono: $\% \mathrm{~V}=9,0($ desvio $=-8)$;

Color: $\% \mathrm{~V}=11,4$ (desvio $=-4)$.

No caso, a insuficiente utilização dos padrões de pensamento do adulto ocorre em todo protocolo, mas sobretudo em situações que solicitam reflexão e iniciativa.

Ligação emocional com o ambiente (interesse): \%A

Mono: $\% \mathrm{~A}=30,4($ desvio $=-4,6)$;

Color: $\% \mathrm{~A}=22,9($ desvio $=-5,1)$.

Insuficiente participação emocional nos eventos externos, no caso decorrente de dispersão da atenção.

- Adaptação às exigências da realidade : Rmi

Este processo não se confunde com a noção da realidade, embora dela dependa. Ele se desenvolve no curso do desenvolvimento individual, permitindo a integração refletida às condições observadas no ambiente.

Mono: 31,1 (desvio = -12);

Color: 27,3 (desvio $=-12,7)$.

O paciente não consegue adaptar-se às exigências externas por causa do comprometimento global dos processos cognitivos envolvidos neste processo.

\section{Esquizofrenia paralógica}

- Julgamento de realidade : $\% \mathrm{~F}+$

Mono: $\% \mathrm{~F}+=0($ desvio $=-80,0)$;

Color: $\% \mathrm{~F}+=25,0($ desvio $=-75 \%)$.

Alteração no julgamento da realidade com comprometimento acentuado no raciocínio, especialmente quando solicitado a refletir e tomar decisões (mono).

- Adoção dos padrões de pensamento do adulto: \%V

Mono: $\% \mathrm{~V}=0($ desvio $=-17)$;

Color: $\% \mathrm{~V}=8($ desvio $=-8)$.
No caso, a insuficiente utilização dos padrões de pensamento do adulto ocorre em todo protocolo, mas sobretudo em situações que solicitam reflexão e iniciativa.

- Ligação emocional com o ambiente (interesse): $\% \mathrm{~A}$

Mono: $\% \mathrm{~A}=0($ desvio $=-35)$;

Color: $16,0($ desvio $=-12)$.

Insuficiente participação emocional nos eventos externos, apenas mantém uma frágil ligação com a realidade externa quando estimulado afetivamente.

-Adaptação às exigências da realidade: Rmi

Mono: 0 (desvio = -4$)$;

Color: 16,4 (desvio $=23,6)$.

O paciente não consegue organizar o seu pensamento de modo a julgar as condições do ambiente objetivo, concepções irracionais interferem na capacidade de integrar-se às exigências da realidade. Permanece como observador passivo, com reduzido interesse pelo que se passa a seu redor, e apenas o estímulo afetivo direto aproxima o examinando dos demais.

\section{Fantasiofrenia}

- Julgamento de realidade : $\% \mathrm{~F}+$

Mono: $\% \mathrm{~F}+=50,0($ desvio $=-30)$;

Color: $\% \mathrm{~F}+=50,0($ desvio $=-26)$.

Alteração no julgamento da realidade por causa da intervenção de julgamento de valor.

- Adoção dos padrões de pensamento do adulto: \%V

Mono: $\% \mathrm{~V}=33,3($ desvio $=0)$;

Color: $\% \mathrm{~V}=12,5$ (desvio $=-4,5)$.

No caso, insuficiente utilização dos padrões de pensamento do adulto ocorre exclusivamente quando o exame encontra-se sob impacto afetivo.

- Ligação emocional com o ambiente (interesse): \% A

Mono: $\% \mathrm{~A}=83,3($ desvio $=+3)$;

Color: $\% \mathrm{~A}=0($ desvio $=-35)$.

Neste caso observa-se uma acentuada ruptura na ligação emocional do examinando ao ambiente: em circunstâncias impessoais, ele se apega ao ambiente de modo ester eotipado e convencional; entretanto, quando envolvido afetivamente em uma situação, desaparece o seu vínculo emocional com o ambiente, prevalecendo interesses de ordem pessoal.

-Adaptação às exigências da realidade : Rmi

Mono: 55,5 (desvio = 0);

Color: 20,8 (desvio $=19,2)$. 
Diante de situações impessoais o examinando submete-se às exigências da realidade, porém delas se afasta quando se envolve afetivamente.

\section{Esquizofasia}

-Julgamento de realidade : $\% \mathrm{~F}+$

Mono: $\% \mathrm{~F}+=77,0($ desvio $=-3)$;

Color: $\% \mathrm{~F}+=53,8($ desvio $=-22.2)$.

Ligeira instabilidade no julgamento de realidade, apenas se agrava em condições de ordem afetiva.

- Adoção dos padrões de pensamento do adulto: \%V

Mono: $\% \mathrm{~V}=6,20$ (desvio: $-10,8$ );

Color: $\% \mathrm{~V}=13,6($ desvio $=-3,6)$.

No caso, a insuficiente utilização dos padrões de pensamento do adulto ocorre sobretudo em situações que solicitam reflexão e iniciativa. Portanto, afetivamente o paciente identifica-se com os valores convencionais de conduta, apenas não consegue utilizá-los de modo refletido e formal.

- Ligação emocional com o ambiente (interesse): \%A

Mono: $\% \mathrm{~A}=25,0($ desvio $=-10,0)$;

Color: $\% \mathrm{~A}=9,0($ desvio $=-19)$.

Insuficiente participação emocional no ambiente, decorre no caso da dificuldade que encontra em expressar seus interesses. Quando estimulado afetivamente a atenção dispersa-se e a sua ligação com o ambiente torna-se mais instável.

-Adaptação às exigências da realidade : Rmi

Mono: 36,1 (desvio = -7,9);

Color: $25,5($ desvio $=-14,5)$.

A dificuldade que o paciente encontrapara integrar-se às condições do ambiente resulta de dinamismo diverso para cada tipo de experiência: diante de situações que solicitam decisão refletida, o examinando, embora mantenha a noção da realidade, não orienta o seu raciocínio de acordo com concepções básicas ao convívio interpessoal: quando estimulado afetivamente, reage de modo demasiadamente subjetivo, perdendo de vista as exigências da realidade.

\section{Comunicação: categorias de conteúdo}

As categorias indicam a gama de interesses e preocupações do examinando. Entre elas distinguimos as figuras humanas percebidas integralmente $(\mathrm{H})$ ou parcialmente $(\mathrm{pH})$, assim como as imagens referentes ao interior do organismo (ao) a doenças (na).

\section{Embotamento incoerente}

- H:pH=1:2 (São Cosmo (V); braço de gente em pássaro (III) e pernas em um corpo aberto $(\mathrm{X})$; $\% \mathrm{RH}=\mathbf{5 \%}($ desvio $=\mathbf{- 1 5})$.

Faixa reduzida de interesses (6 categorias) por causa da perseveração em conteúdos anatômicos (an = 28), além da elevada ocorrência de imagens de sangue $(\mathrm{sg}=4)$ e sexo $(\mathrm{sx}=5)$, indicando predomínio de preocupações de ordem pessoal e afetiva.

\section{Esquizofrenia paralógica}

- H:pH=1:1 (figura humana imprecisa e neutra (VII), mãos (I); \% RH = 5 (desvio = -15).

Adequada faixa de interesses (8 categorias), apesar de prevalecer aqueles de ordem mais concreta, ligados à vida cotidiana ou ao seu trabalho de lavrador. Ocorrência de perseveração no conteúdo alimento, percebido como frutas ou legumes $(\mathrm{al}=10)$; além deste, também ocorreu em número elevado os conteúdos de objeto $(o b j=9)$ e botânica $(b t=6)$.

Dificuldade em coordenar o seu pensamento. Por causa da alteração na observação abstrata, o resultado de suas concepções são incompreensíveis e não seguem a lógica formal. As paralogias são freqüentes em seu discurso, o que torna difícil a compreensão. Baseia-se em dados da realidade, mas o seu pensamento é falso. Não consegue definir os conceitos mais simples.

\section{Fantasiofrenia}

$$
\begin{gathered}
\cdot \mathbf{H}: \mathbf{p H}=\mathbf{1 : 0} \text { (marionete III); } \\
\% \mathbf{H}=7 \%(\text { desvio = -13) }
\end{gathered}
$$

Faixa reduzida de interesses ( 4 categorias) por causa da perseveração em concepções estéticas categorizadas de modo superficial, mas com abundância de adjetivos ( $\operatorname{art}=5$, arq =1), apenas percebe uma figura humana, estando ausente qualquer conteúdo orgânico ( $\mathrm{an}=0, \mathrm{sg}=0, \mathrm{sx}=0$ ).

\section{Esquizofasia}

- H:pH=5:5 (Pessoa (III), Freira (IX), doutor $(\mathrm{X})$, boneca $(\mathrm{X})$, as pH são cabeça $(2)$, dedo

(2) e dentes; \% RH $=26 \%($ desvio $=0)$ an $=2$.

Adequada faixa de interesses ( 9 categorias), destacando-se aqueles relativos ao comportamento humano, porém sua dificuldade em categorizar de modo pertinente suas experiências acarreta generalizações arbitrárias $(a b=6)$.

Ocorrem parafasias verbais e agramatismos, além de tropos verbais, como sinédoque (partes para designar o todo), metonímia (função para designar o objeto). Às vezes, encontramos em seu discurso uma "salada associativa" desprovida de qualquer nexo lógico. 


\section{Percepção da situação da prova - Intervenção dos mecanismos de reação}

1. Embotamento incoerente: Ao olhar para a primeira prancha, comenta: "Sobre o corpo humano né?" Em todas as pranchas, além de outras poucas respostas, o paciente percebe vísceras humanas ou animais (perseveração). Referindo-se à evolução das espécies. Em algumas associações ele não distingue os limites entre interno e externo (limite) e, em todas elas, a posição relativa das manchas é usada como principal critério para distinguir um órgão do outro (posição).

2. Esquizofrenia paralógica: Todas as pranchas são percebidas como uma unidade: "Um papel cinzento que deve representar alguma coisa". Procurando encontrar um conceito, o paciente faz deslocamentos de imagens, aproximações arbitrárias formando novas imagens paralógicas. No inquérito do Rorschach ficou evidente que o examinando interpreta os estímulos ambíguos como representações convencionais (cheque, bilhete, papel), considerados como "roupa" que estão no lugar dos objetos concretos que não aparecem, "são cegos", obececendo a uma lei ou à gramática. Ex. I: "É um cheque de dinheiro, sistema de uma roupa para assinar um papel". II: "O papel serve porque, se por acaso alguém quer comer um bolinho, ele determina que ele pode comer." X: "Este é um bilhete que serve para esconder a comida e as bebidas. Elas são cegas no bilhete. Se alguém quer beber dá o bilhete ao patrão. É a gramática que diz isto". (Para o paciente "roupa" corresponde à convenção e gramática, à lei.)

3. Fantasiofrenia: Os estímulos do Rorschach foram considerados realidade integrada junto com os objetos da sala. I: "Umas borboletas que nem morcego que avoa, que nem morcego que tem nas matas virgens. Tanto quanto eu vi lá (aponta para a cortina da sala), aqui tem muitas aranhas perigosas e pensei será que eram aranhas voadoras? Depois ela saiu daqui voando e eu vi que era borboleta".

4. Esquizofasia: Considera prova como: "Bogologia, coisas que a gente pensa depois faz. A Bogologia maior era a Astrologia Fenomenal", e, após dar a sua primeira resposta, comenta: 'É uma coisa formal que sai idéias fixas de coisas brancas. As pessoas que se unem que se entendem, fazem sinal e pensa. É uma idéia abominável". Sua preocupação em comunicar suas respostas mantém-se ainda na segunda prancha: "Abismo é coisa conjunta, que forma pessoas finas, uma professora, uma médica. Engraçado que, quando a pessoa não alcança, ela não dá diploma. Só dá diploma para quem alcança... Mas eu não faço enquanto a doutora não acusa a cabeça normal". Afastamento do estímulo em um processo de associação de idéias, levando à formulação de paralogias e parafasias. Exemplos: VI (P1): "Gaveta fechada. Na gaveta a gente põe a idéia que nem o livro. A idéia tem altura, o médico, o professor, o tenente, um aspirante, guarda tudo na gaveta. O Borges é o oblíquo do pensamento... é coisa útil." VIII: "Fuzilamento de Aureal de pom-póm. Tem uns riscos aqui. Ele sabe que tem risco, que não tem a terra. Ele quer ser doutor que nem o geral. O general é que formou a estrela nacional. Não tem sentido, ele é só advérbio. Isto é bom para a pessoa ser doutor... era bom ter gente assim no país, aqui é só analfabeto. Um bebê é um ornamento são, direito, que o parteiro aquece."

\section{Síntese dos resultados encontrados na prova de Rorschach}

Examinamos para cada paciente os diferentes níveis dos processos cognitivos. Destacaremos as principais características encontradas, mencionando os mecanismos anormais que intervieram no processo associativo. O quadro que sintetiza os desvios mais significativos encontra-se anexo no fim do texto.

\section{Observação}

Do ponto de vista quantitativo os índices dos diferentes pacientes não difere daqueles que encontramos em indivíduos normais: o fato de ser capaz de integrar os diferentes aspectos do estímulo em um conceito único $(\mathrm{G})$, de dar atenção às áreas mais salientes dos estímulos (P) e mesmo de o olhar ser atraído pelas minúcias (p) ou ser capaz de perceber o fundo do estímulo como figura (reversão figura-fundo em E). O que difere é a noção que decorre da apreciação dos estímulos e o modo com que estes pacientes utilizamse destas áreas para a atribuição de significados. Neste caso, a distinção entre o conjunto de estímulos monocromáticos e o dos coloridos é elucidativa. A instabilidade no modo de apreciar os fatos foi assinalada nos quadros Incoerente e sobretudo no paralógico, sendo que no primeiro a mudança faz-se na modalidade de observação concreta ( $\mathrm{P} 2$ para $\mathrm{p} 2$ ), enquanto no segundo ela decorre de alteração na observação abstrata (G2 para P2), e o estilo perceptual mantémse nos outros dois quadros clínicos. Além disso, apenas nos quadros Incoerente e paralógico a seqüência dos movimentos oculares faz-se de modo desordenado (Suc incoerente). Por outro lado, em todos os pacientes do grupo confusional a apreensão global $(G)$ não resulta de um reconhecimento genérico do padrão 
estrutural da mancha, mas decorre de impressões imediatas que provocam impacto emocional e que, por vezes, se organizam de modo sincrético, aglutinado. A apreensão das áreas cuja gestalt impõe-se mais facilmente à atenção $(\mathrm{P})$ foi assinalada em três protocolos, mas é ausente no protocolo de fantasiofrenia. Porém, nesses pacientes, a focalização nessas áreas provocou impressões subjetivas e imediatas e elas foram interpretadas de modo precipitado ou então combinadas de modo arbitrário, indicando alteração na percepção dos dados concretos e evidentes das situações, indis pensável ao rendimento da atividade prática. A atenção às demais áreas dos estímulos evocou apenas imagens vagas com escassa delimitação formal: pormenores secundários (p) nos quadros embotamento incoerente e esquizofrenia paralógica, espaços em branco entre as manchas (E), nos quadros de esquizofasia e fantasiofrenia, no último o examinando integrou-as a significados genéricos e afetivos (GE).

Subjacente ao modo de os examinandos distribuírem sua atenção ao ambiente foram assinalados alguns mecanismos que interferem de modo patológico na interpretação dos estímulos: o mecanismo posição que ocorre no quadro incoerente resulta da noção irracional de que o modo como os eventos, os objetos ou as pessoas posicionam-se no ambiente é indicativo de um valor ou significado; o mecanismo concretismo encontrado no quadro paralógico indica dificuldade de abstração e consideração inadequada das propriedades dos estímulos como objetos concretos do ambiente.

\section{Elaboração}

A construção das imagens a partir da observação dos estímulos implica a capacidade de o examinando confrontar a experiência atual - no caso, as propriedades estruturais das manchas - com aquelas do passado. A elaboração indica o modo com que o pensamento articula-se durante a interpretação de uma situação. Este processo foi estudado do ponto de vista quantitativo, como capacidade de conceber imagens ou conceitos a partir de estímulos ambíguos, que correspondem a situações novas ou inusitadas, indicando o grau de mobilização da memória para a execução da tarefa (R). No caso, o número de associações $\mathrm{R}$ é relativamente baixo no quadro de fantasiofrenia, em que o fluxo associativo intenso não permitiu a consolidação de conceitos, sobretudo quando o examinando encontrase sob impacto afetivo direto. $\mathrm{O}$ número de respostas apenas encontra-se elevado no grupo incoerente, em virtude da expressão imediata de impressões emocionais, diretamente comunicadas como intervenção mínima da elaboração (número elevado de imagens R1 em todo o protocolo).
Do ponto de vista qualitativo a análise é feita na maneira com que as imagens foram construídas (R1 a R6), mas também no modo com que se organizam entre si de maneira a serem fixadas na memória. Esta organização pode decorrer de um pensamento racional e dedutivo (Z1) ou aglutinação arbitrária e irracional de aspectos díspares das experiências aos quais tem primazia o valor afetivo (Z2). Em todos os protocolos os valores de Z2 superaram os de Z1, ainda que do ponto de vista quantitativo ambos apresentem valor reduzido, indicando redução na capacidade de elaboração das experiências. $\mathrm{O}$ confronto dos valores de $\mathrm{Z} 1$ e Z2 nos conjuntos de estímulos monocromáticos e coloridos nos permite uma distinção entre os quadros estudados: na fantasiofrenia, apenas quando sob estímulo afetivo direto (conjunto cromático) é que se eleva a elaboração irracional (Z2), sendo nula a elaboração realista das situações $(Z 1=0)$; já diante de situações que não envolvam impacto afetivo (conjunto monocromático), o pensamento racional tem primazia $(\mathrm{Z} 1>\mathrm{Z} 2)$. Na esquizofasia ocorre a tendência inversa, ou seja, apenas quando o examinando defronta-se com situações que exijam reflexão e iniciativa (monocromáticas) é que as concepções pautadas em julgamentos de valor têm primazia sobre o raciocínio lógico $(\mathrm{Z} 2>\mathrm{Z} 1)$, enquanto que estímulo afetivo reduz a diferença entre os tipos de elaboração, havendo uma redução acentuada do pensamento irracional. Nos dois outros casos, o pensamento irracional prevalece em todo protocolo.

Em todos os pacientes do grupo confusional a construção indutiva de imagens pelo reconhecimento do padrão estrutural dos estímulos é extremamente rara: a imagem R2, cuja freqüência é reduzida nesses pacientes, pois o valor global dos desvios em relação à ocorrência assinalada para esta imagem na população normal foi o de -53 no incoerente, -87 no paralógico, -58 na fantasiofrenia e relativamente menos acentuado, -25 , no esquizofásico. As imagens construídas pela integração de diferentes propriedades dos estímulos (R3) apenas foram encontradas no quadro esquizofásico, cujo distúrbio central situa-se na expressão verbal, e apenas de modo secundário na elaboração da imagem. Porém, neste quadro, a imagem R3 ocorreu com freqüência ligeiramente inferior àquela encontrada na população normal (desvio de -8). Outro aspecto interessante é a total ausência nesses protocolos de imagens cuja presença nos protocolos de indivíduos normais indica capacidade de integração das experiências sociais de modo autônomo e refletido (R5) ou imaginação e criatividade (R6).

Assim, nos protocolos em estudo prevalecem as imagens cuja construção pauta-se predominantemente em reações ou concepções irracionais (R1 e R4). 
A interferência direta da emoção na capacidade de elaboração das experiências resulta na imagem $\mathrm{R} 1$, cuja ocorrência é elevada em todos os protocolos, mas principalmente no quadro incoerente (desvio global é de +99) e em menor grau no quadro paralógico (+24). As imagens sincréticas, que aglutinam em um único conceito diferentes nexos emocionais, não sendo o indivíduo capaz de selecioná-los em função das propriedades objetivas dos estímulos, corresponde à modalidade R4, cuja ocorrência é elevada em todos os protocolos, mas sobretudo no quadro paralógico, em que sua freqüência é mais de quatro vezes superior à dos demais grupos (desvio global atinge +132 ), e com reduzida frequiência no quadro esquizofásico (desvio global de +2 ).

A mobilização pertinente dos recursos subjetivos fixados na memória e disponíveis para a adaptação à situação atual (Lambda) acha-se comprometida nos quatro protocolos, em que a memória afetiva de concepções irracionais interferem no trabalho mental, comprometendo a interpretação adequada de novas experiências. Entretanto, a intensidade com que este processo desencadeia-se é diversa em cada quadro estudado. No embotamento incoerente esse processo ocorre de modo instável: o estímulo afetivo o inibe, enquanto as circunstâncias interpessoais o amplia intensamente. Na esquizofrenia paralógica, a mobilização desse processo apenas se reduz quando o examinando encontra-se sob impacto afetivo. $\mathrm{Na}$ fantasiofrenia, a interferência da memória afetiva faz-se de modo acentuado em todo protocolo, embora se amplie significativamente quando a afetividade é estimulada de modo direto. Na esquizofasia a intensidade desse processo diminui em todo o protocolo, porém sua qualidade é melhor, tendo em vista a diversidade de recursos que dispõe (FC, Ps, $\mathrm{C}^{\prime}$ ).

Entre os mecanismos anormais que interferem na elaboração das experiências, destacamos o fluxo associativo, em que o curso do pensamento torna-se disperso afastando o paciente das experiências imediatas. Este mecanismo foi assinalado nos quadros paralógico e na fantasiofrenia, mas ocorreu de modo acentuado em todo o protocolo do paciente esquizofásico. Outro mecanismo, a fabulação, ou seja, a projeção de significados pessoais, sentimentos ou intenções nas imagens percebidas, aparece com maior intensidade no protocolo do quadro fantasiofrenia.

A condensação, em que ocorre uma combinação arbitrária e irracional de diferentes imagens subjetivas, por causa da mobilização de fantasias infantis e nexos emocionais primários despertados pela situação atual, é um mecanismo que foi assinalado nos quadros incoerente e sobretudo no paralógico.
$\mathrm{O}$ mecanismo perseveração, embora de origem conativa, pelo excesso de manutenção da atenção e um único ser da realidade, intervém na elaboração do pensamento. Ele foi dominante no quadro de embotamento incoerente.

\section{Processo de adaptação à realidade}

$\mathrm{O}$ processo de adaptação à realidade (Rmi) ocorre pelo concurso harmônico e integrado da capacidade de julgar de modo objetivo e imparcial os fatos $(\mathrm{F}+)$, da assimilação dos padrões de pensamento e de conduta adotados pela maioria $(\% \mathrm{~V})$ e da ligação emocional espontânea ao ambiente (\%A).

Esse processo acha-se comprometido em todo o protocolo nos quatro casos, com a ressalva de que na fantasiofrenia esta alteração ocorre apenas quando o examinando é estimulado afetivamente.

A análise desse processo indica que o comprometimento assume diferente feitio em cada caso: no embotamento incoerente acham-se particularmente comprometidos o julgamento de realidade e, em menor grau, a utilização dos padrões convencionais de pensamento e a ligação emocional ao ambiente. Na esquizofrenia paralógica acham-se gravemente comprometidos os três fatores envolvidos no processo de adaptação ao ambiente: o julgamento da realidade, a integração cognitiva e afetiva aos padrões convencionais de pensamento e a ligação emocional ao ambiente. $\mathrm{Na}$ esquizofasia é menor o comprometimento no julgamento de realidade, sobretudo em circunstâncias afetivamente neutras, sendo que, como contraponto, o estímulo afetivo direto facilita a utilização dos padrões sociais de pensamento, porém sua ligação emocional com o ambiente acha-se globalmente comprometida, afetando a adaptação à realidade.

Na fantasiofrenia a dinâmica é variável, embora o julgamento de realidade encontre-se globalmente comprometido: em situações que não envolvam os sentimentos pessoais, o examinando consegue pautar seu comportamento segundo padrões convencionais de pensamento, elevando a sua ligação emocional com o ambiente e, assim, adaptando-se à realidade. Entretanto, quando se encontra sob impacto afetivo afasta-se dos padrões convencionais de pensamento e mantém escassa ligação emocional ao que ocorre ao seu redor, o que impede sua adaptação às exigências da realidade.

\section{Comunicação}

Já mencionamos as dificuldades específicas reveladas pelos pacientes ao comunicarem verbalmente o resultado do trabalho mental, sendo mais acentuadas na esquizofasia. 
As categorias de conteúdo indicam a faixa de interesses dos examinandos, e que se acha reduzida nos casos de embotamento e sobretudo na fantasiofrênia. No que se refere ao interesse específico pelo comportamento humano, verificamos que apenas no quadro esquizofásico a figura humana foi percebida com maior freqüência, enquanto nos demais ela se acha praticamente ausente. É interessante lembrar aqui o fato de o esquizofásico apresentar como desordem central a dificuldade em categorizar verbalmente as experiências; de resto isto fica evidente com a presença acentuada dos mecanismos relacionados a desordens de comunicação: agramatismo, neologismo, parafasias, metonímia e sinédoque. Porém, apesar desta dificuldade, o protocolo deste examinando foi o que apresentou maior variedade de interesses, inclusive os de ordem abstrata; além disso, foi o único que elaborou imagens que exigem maior esforço de construção (R3). Isto indica que a capacidade de elaboração e o interesse do examinando mantêm-se, apesar de sua dificuldade em expressar de modo adequado o seu pensamento.

O mecanismo contaminação, considerado pelos especialistas em Rorschach como característico em protocolos de psicóticos, envolve de modo mais complexo o comprometimento de todo o trabalho mental, desde o nível da observação, o processo de evocação seletiva das experiências e a elaboração de imagens, até o seu modo de codificá-las. Neste mecanismo ocorre uma sobreposição de imagens evocadas por associações diferentes, mas que se fundem em um único conceito. Este mecanismo expressa-se quando o examinando verbaliza o seu conceito, não conseguindo optar por uma das categorias que se acumulam em uma única imagem. Este mecanismo foi assinalado na maioria dos protocolos, porém não ocorreu na esquizofasia.

\section{Conclusão}

Esperamos ter aqui evidenciado a contribuição que o exame psíquico efetuado por meio da prova de Rorschach pode trazer não apenas para a clínica psiquiátrica, mas para estudos experimentais sobre os processos mentais e suas diversas formas de comprometimento. Nesse caso, a ocorrência de desvios de cada uma das funções, assim como dos processos direta ou indiretamente envolvidos na atividade cognitiva (atenção, percepção, memória, raciocínio, emoção, simbolização e linguagem), tal como se expressam na prova de Rorschach, poderão ser ulteriormente examinados de modo mais específico com auxílio de testes neuropsicológicos para cada tipo de desvio, de modo a obter-se um quadro completo dos transtornos psicopatológicos, caso se pretenda fazer estudos experimentais sobre a esquizofrenia.

\section{Súmula dos principais desvios cognitivos}

Desvios mais acentuados $(+)$, mais atenuados (-) ou ausentes (0)

\section{Observação}

1. Instabilidade no modo de distribuir a atenção (Perc mono/color e má qualidade formal):

$$
\begin{aligned}
& \text { Paralogia (+) } \\
& \text { Esquizofasia (-) }
\end{aligned}
$$

2. Integração sincrética das experiências (G e P sinc.):

$$
\begin{aligned}
& \text { Paralogia (+) } \\
& \text { Esquizofasia (-) }
\end{aligned}
$$

3. Desorganização na observação seqüencial dos fatos (SUC):

$$
\begin{aligned}
& \text { Incoerente = paralogia }(+) \\
& \text { Fantasiofrenia }(0)
\end{aligned}
$$

4. Dificuldade de apreensão dos dados concretos das experiências (P em Perc):

$$
\begin{aligned}
& \text { Fantasiofrenia (+) } \\
& \text { Esquizofasia (0) }
\end{aligned}
$$

\section{Elaboração}

1. Liberação associativa por interferência emocional ( $R$ e R1 elevados):

$$
\begin{aligned}
& \text { Incoerente (+) } \\
& \text { Paralogia (-) }
\end{aligned}
$$

2. Escassez do raciocínio indutivo ( $R 2$ reduzido) e alteração do raciocínio dedutivo (R4 elevado):

$$
\begin{aligned}
& \text { Paralogia (+) } \\
& \text { Esquizofasia (-) }
\end{aligned}
$$

3. Elevada interferência da elaboração irracional $(\mathbf{Z} 2>\mathbf{Z 1})$ :

Em todo protocolo: Incoerente (+)

Ativação afetiva direta:

Fantasiofrenia Esquizofasia (-)

4. Baixo rendimento qualitativo da memória de trabalho (Lambda e fatores determinantes):

Incoerente (+)

Esquizofasia (-) 
Desvios no processo de adaptação à realidade

\section{Situação formal}

Interferência no julgamento de realidade $(\% \mathrm{~F}+)$ :

Paralogia (+ )

Esquizofasia (-)

Integração insuficiente do padrão social de pensamento (\%V):

Paralogia (+)

Fantasiofrenia (0)

Instabilidade na ligação emocional ao ambiente $(\% \mathrm{~A})$ :

Paralogia (+)

Fantasiofrenia (-)

Comprometimento global do processo (Rmi):

Paralogia (+)

Fantasiofrenia (0)

Situação de impacto afetivo

Interferência no julgamento de realidade $(\% \mathrm{~F}+)$ :

Paralogia (+)

Esquizofasia (-)

Integração insuficiente do padrão social de pensamento $(\% \mathrm{~V})$ :

Paralogia (+)

Esquizofasia (-)

Instabilidade na ligação emocional ao ambiente $(\% \mathrm{~A})$ :

Fantasiofrenia (+)

Incoerente (-)

Comprometimento global do processo (Rmi):

Paralogia (+)

Incoerente (-)

\section{Comunicação}

Escassa representação da figura humana:

Paralogia (+)

Esquizofasia (0)
Faixa reduzida de categorias de conteúdos:

Fantasiofrenia (+)

Esquizofasia (0)

Transtornos da linguagem:

Esquizofasia (+)

Fantasiofrenia (-)

Mecanismos anormais de reação mais freqüentes para cada grupo:

\section{Observação:}

Incoerente (Pos, Lim, Persev)

Elaboração:

Paralogia (condensação)

Fantasiofrenia (fabulação, liberação associativa)

Esquizofasia (fluxo associativo)

Referências bibliográficas

BARLOw, H. et al. - Images and Understanding. Cambrige University. Press, New York; 1990.

Bastien C. - Les Connaissances de l' enfant à l'adulte. Armand Colin, Paris; 1997.

Coelno L. et al. - Rorschach Clínico. Terceira Margem, São Paulo; 2002.

Coelno, L. Epilepsia e Personalidade. Editora Ática, São Paulo; 1980.

Coelho, L. - "Notion de Réalité et Processus D'Adaptation Cognitive Chez des Schizophrènes par L'épreuve de Rorschach". Comunicação apresentada no X Congresso Internacional de Rorschach realizado em Washington;1981.

Coelno, L. - Análise cognitivista do processamento de imagens. Comunicação apresentada ao XIV Congresso Internacional de Rorschach, realizado em Lisboa; 1992.

Edelman, G. - Bright Air, Brilliant Fire-On the Matter of the Mind. Penguin Books, London; 1992.

LAZArus, R. - Emotion and adaptation. Oxford University Press, New York; 1991.

Silveira, A. - Cerebral systems in the pathogenesis of endogenous psychoses. Arquivos de Neuro-Psiquiatria: 20 (4): 263-78, 1959.

Silveira, A. - Prova de Rorschach. Elaboração do Psicograma. Brasileira, São Paulo; 1985.

SiLVEIRA, A. - Caracterização da patologia cerebral, da psicopatologia e da heredologia psiquiátrica na doutrina de Kleist. Arquivos de Neuro-Psiquiatria 17;(2): 1959.

T iberghien, G. - La mémoire oubliée. Mardaga, Paris; 1997

Vizzotto, S.; Melshon, I. - Esquizofasia. Trabalho realizado no Hospital Juqueri, 1959 